\title{
iQue se vayan todos, que no quede uno solo! La crisis institucional en Chile: factores contributivos del socavamiento de las bases culturales de la democracia (1990-2019)
}

\author{
Nelson Alejandro Osorio Rauld \\ UNIVERSIDAD COMPLUTENSE DE MADRID, ESPAÑA \\ nelsonos@ucm.es
}

Resumen: El artículo analiza algunos factores institucionales y estructurales que han contribuido progresivamente a un divorcio entre ciudadanía y representantes en el caso chileno. Este distanciamiento entre política y sociedad ha sido denominado por diversos autores como «crisis institucional». Se sostiene que existe una amalgama de elementos que han contribuido decididamente a este socavamiento de las bases culturales de la democracia, entre los que se encuentran, el diseño institucional de democracia protegida con sus enclaves autoritarios, los repetidos casos de corrupción que han minado la confianza ciudadana, además de una crónica mala distribución de la riqueza. Estos elementos han sido muy relevantes en la producción de una creciente desafección política que ha devenido en fuertes movilizaciones sociales, las que han puesto en cuestionamiento la legitimidad de las instituciones democráticas.

Palabras claves: democracia, instituciones, cultura política, democracia protegida, desigualdad, ciudadanía

Abstract:The article analyzes some institucional and structural factors that progressively have contributed to a divorce between citizen and representatives in the Chilean case. This rupture has been called by a different authors as a «institucional crisis». The hyphotesis indicates that there is an amalgam of elements that have contributed strongly to this undermining of the cultural bases of democracy, among them, the "democracia protegida» and its authoritarian enclaves, systematic corruption cases that have destroyed citizen confidence, but also, a historical inequality that has affected the country. All this elements have been important in fostering a growing political disaffection, which has led to strong social movements that have challenged the legitimacy of democratic institutions.

Keywords: democracy, institutions, political culture, democracia protegida, inequality, citizen.

\section{Introducción}

l presente trabajo analiza lo que se ha denominando como «crisis institucional» en Chile: concepto que ha sido acuñado y divulgado sobre todo por intelectuales y políticos pertenecientes al mundo del centroizquierda. Su refutación, en cambio, es desarrollada por líderes y expertos próximos al sector del centroderecha, 
desde donde se desestima la existencia de una «crisis institucional». Desde esta posición más bien se señala una baja confianza ciudadana producto del deficiente desempeño de las instituciones democráticas, sin que dicha situación ponga en riesgo la estabilidad del propio régimen político.

En segundo lugar, el artículo analiza algunos factores que han sido relevantes en producir una fuerte desafección en la ciudadanía hasta el año 2019: cinismo político, apatía, distanciamiento, entre otros fenómenos similares que se expresan en distintos indicadores, como una baja participación electoral, una prolongada y creciente desconfianza hacia los partidos y el Congreso, un declinante apoyo a la democracia, una oscilante desaprobación del ejecutivo independientemente del signo político, entre otras valoraciones que levantan alarmas respecto a cómo la ciudadanía está percibiendo desde hace largo tiempo a sus representantes. Los elementos analizados, bien pueden ser contributivos para ayudar a comprender la naturaleza explosiva del actual estallido social que tiene lugar en el país, el que ha mostrado las limitaciones y problemas del actual modelo político y socioeconómico.

Aunque es siempre materia de análisis y debate en el campo de la cultura política, el presente trabajo sugiere que algunos factores son más decisivos que otros en la incidencia de esta crisis. Es el caso del defectuoso desarrollo socioeconómico que ha tenido lugar en el país, siendo éste una «variable independiente» en la producción de este divorcio entre ciudadanía y política. Otros elementos asociados al desempeño de las instituciones como los repetidos casos de corrupción, el encapsulamiento de los partidos y el lento proceso de consolidación democrática, son igualmente relevantes, no obstante, el atrevimiento consiste en señalar que dentro de esta amalgama compleja de elementos, su peso puede ser un tanto menor respecto del factor distributivo que históricamente ha afectado a la sociedad chilena.

Lo anterior obliga a volver la vista sobre la relación entre institucionalidad y desarrollo socioeconómico, atendiendo a algunos de los problemas que ha presentado la estrategia de democratización sobre la base del crecimiento económico como único factor a considerar. En ésta no se ha prestado la debida atención a la dimensión distributiva, lo que ha influido sistemática y negativamente en el socavamiento de las bases culturales de la democracia chilena.

\section{2. ¿Crisis institucional o bajo desempeño de la instituciones democráticas?}

Varios rankings internacionales ${ }^{1}$ siguen reconociendo a la democracia chilena como una de las más saludables de la región. En estos informes, se subraya, fundamen-

1. Sólo como muestra véase el índice de democracia de The Economist (2018), el Índice de Desarrollo Democrático de América Latina (2016) y el informe Auditoría a la democracia del Programa de Naciones Unidas (2014). 
talmente, la estabilidad del régimen político y también la calidad de sus procesos electorales. De esta manera, Chile, continúa ocupando un lugar privilegiado dentro del continente, bien acompañado por uruguay y Costa Rica. Ciertamente, sobre la base de la evidencia que aportan estos documentos, se podría verificar que estos tres países tienen los regímenes democráticos más avanzados de la región.

Sin embargo, a pesar de las positivas valoraciones de la comunidad internacional, se estima que existe evidencia suficiente que podría poner en entredicho estas apreciaciones. Ella está relacionada con algunas situaciones que dan cuenta de la baja implicación de la ciudadanía con la actividad política, mostrando, en cambio, un marcado alejamiento respecto de quienes toman las decisiones más importantes para el país. Se trataría de un problema de legitimidad al decir de Linz (1978), que tiene su expresión en una creciente desconfianza por parte del mundo por fuera de las élites (Osorio, 2019). Esta situación bien podría ser conceptualizada tal cual la definen Montero, Gunther y Torcal (1998), quienes definen el fenómeno de la desafección política como «el desinterés, la ineficacia, la disconformidad, el cinismo, la desconfianza, el distanciamiento, la separación, el alejamiento, la impotencia, la frustración, el rechazo, la hostilidad y la alienación. Se trata, por lo tanto, de una familia de conceptos diversos que capta unas orientaciones básicas hacia el sistema politico cuyo denominador común radica en "la tendencia a la aversión de su componente afectivo» (p.25).

Sobre la base de esta definición se puede indagar en las distintas situaciones del estado actual de la cultura política de los chilenos. En ese sentido, se puede señalar que varios indicadores advierten de alicaídas orientaciones políticas en la ciudadanía del país sudamericano, lo que viene ocurriendo desde el cambio de régimen político hasta el actual momento crítico por el que atraviesa el país bajo el segundo mandato del presidente Sebastián Piñera.

Es el caso, por ejemplo, de los niveles de participación electoral, que son de los más bajos de América Latina (CEP, 2017; LAPOP, 2014: 98). Además presentan una caída estrepitosa desde el plebiscito que permitió la salida del general Pinochet en 1988, que tuvo un 90\% de participación (del Campo, 2007), llegando hasta menos de un 50\% en 2017 para elegir al presidente y a congresistas (Fuentes, 2019; Lagos, 2017). Estas cifras son elocuentes en cuanto a la disminución del «compromiso cívico» que tienen los chilenos en citas tales como la elección de autoridades representativas, algo que también se refleja en otras dimensiones como es el desinterés por la política, que según datos recientes de World Values Survey en 2018, llega a poco menos del 70\% (WVS-MORI, 2018: 82).

Si se verifican otras actitudes «difusas» al decir de David Easton, la situación tampoco mejora. Por ejemplo, en relación al apoyo a la democracia, este también manifiesta un declive llegando a un 58\% en 2018, apenas 10 puntos por sobre el promedio de la región (Latinobarómetro, 2018: 16). Algo un tanto parecido ocurre con la mediocre satisfacción que tienen los chilenos con la democracia, que ha ido 
aumentando gradualmente desde 1990 llegando a poco más de 50\% en 2015 (CEP, 2017). Si bien es cierto este promedio puede parecer «aceptable», lo cierto es que es bajo respecto de democracias consolidadas como las de la Unión Europa, ya que dentro de esta zona sobre un $60 \%$ manifiesta estar satisfecho con el funcionamiento de la democracia dentro de sus propios países (Eurobarometer Survey, 2018: 29). Esto ilustra diferencias a tomar en cuenta respecto al caso chileno.

$\mathrm{Al}$ observar otras orientaciones hacia componentes claves del sistema político (Pateman, 2014; Pye, 1965), las valoraciones cambian drásticamente, dando cuenta de una tensión entre apoyo "difuso» a la democracia y un persistente cuestionamiento del funcionamiento de quienes ejercen el poder político (Bargsted y Somma, 2018). Como se puede distinguir en el gráfico 1, una de las principales instituciones de la democracia, los partidos, se encuentran desde hace largo tiempo mal evaluados por la ciudadanía en su desempeño, llegando a cifras alarmantes de desconfianza.

De este descontento tampoco consigue escapar el Congreso, puesto que éste no logra superar el $7 \%$ de confianza en la ciudadanía. Lo mismo vale para instituciones como las Fuerzas del orden, que desde el retorno de la democracia siempre tuvieron una aceptable valoración. Sin embargo, a partir de reiterados casos de corrupción desde 2017, la confianza ciudadana también ha ido disminuyendo en forma acelerada (CERC, 2019).

\section{Gráfico 1}

Confianza en instituciones, 1990-2019

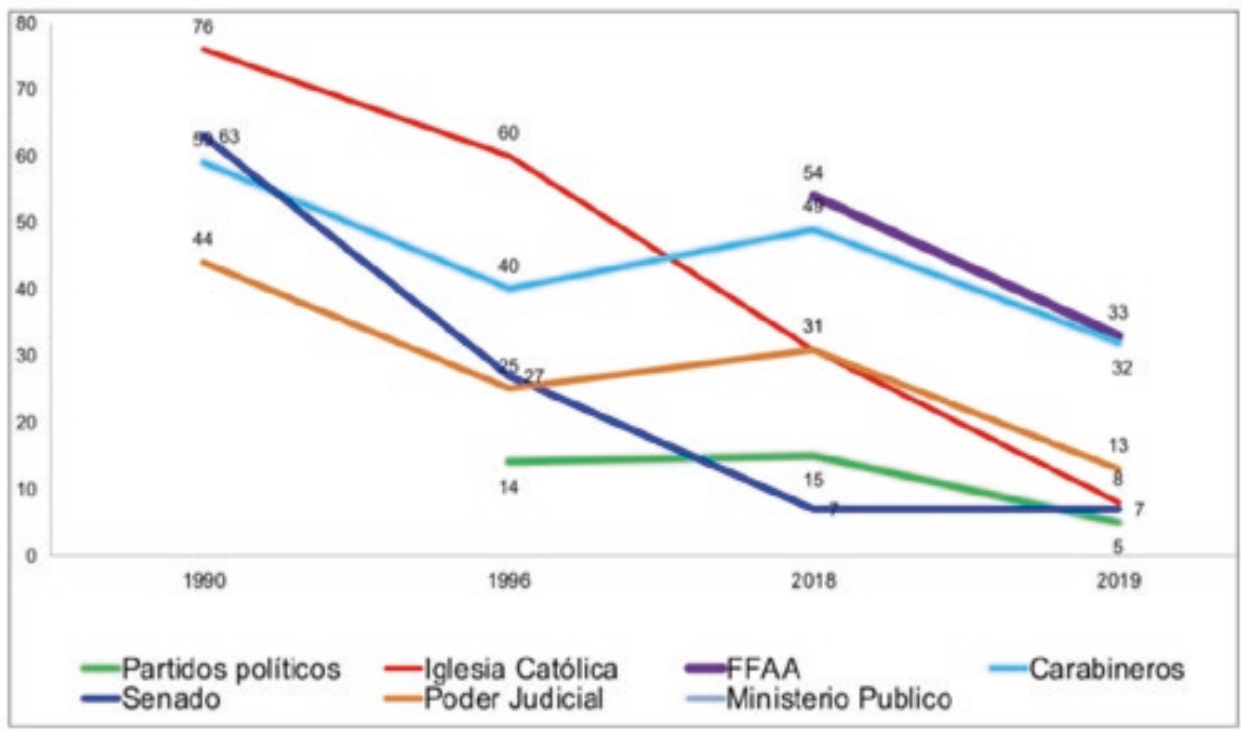


Es conveniente mencionar que la desafección política que hoy tienen los chilenos, es dramáticamente diferente respecto del notorio prestigio que tenía el país por su historia institucional hasta antes del golpe militar de 1973. La literatura que se ha ocupado sobre este tema ha sido categórica en destacar al país sudamericano por sus largos períodos de estabilidad política, subrayando en esta situación la estrecha relación entre sociedad y sus representantes (Valenzuela, 1978; Ruiz, 2005; Moulian, 1994; Luna y Rosenblatt, 2012). De hecho, este desarrollo institucional, inusual para países de la región en este contexto histórico, llevó al mismo Giovanni Sartori a señalar la semejanza del sistema de partidos chileno con algunos de los más avanzados del mundo, como era el caso de Suiza y Finlandia (Sartori, 1976: 313).

No obstante, como los indicadores presentados dejan ver, la situación sociopolítica actual en el caso chileno es lejana respecto de ese prestigio adquirido, lo que ha llevado a líderes políticos de diversa ubicación en el entorno ideológico a plantear la presencia de una «crisis institucional» ${ }^{2}$.

Desde otra arista, la literatura académica que se ha referido a este tema (Garretón 2016 y 2017; Fuentes y Joignant, 2015; LAPOP, 2016; PNUD, 2012 y 2014), conceptualiza esta llamada «crisis institucional» como una suerte de distanciamiento entre quienes ejercen el poder político y la ciudadanía, entendiendo este divorcio como una agudización de la "aritmética representativa» (Bourdieu, 2001), en la que pareciera no haber convergencia o intersección entre representantes y representados. Desde el mundo intelectual y político del centroizquierda, esta negativa situación política se conceptualiza como «(...) un progresivo encapsulamiento de los partidos políticos respecto de la ciudadanía y sus organizaciones; la personalización de la acción política que ha estimulado el clientelismo en relaciones entre electores y actores políticos; y recientes escándalos de corrupción que han afectado transversalmente a la mayoría de los partidos tradicionales, lo que ha generado una distancia todavía mayor entre ciudadanía y partidos. En un contexto de creciente cuestionamiento social y político respecto de la forma en que se distribuye el poder en la sociedad, emergen presiones para cambiar las reglas del juego político en democracia» (Fuentes y Joignant, 2015: 21-22).

Por el contrario, desde los sectores más próximos al centroderecha, se desestima la existencia de una «crisis institucional» y más bien se advierte un problema de desconfianza que se viene produciendo, sobre todo, por un bajo desempeño de las instituciones políticas (CEP, 2017; Lyd, 2013). Ha contribuido a esta situación la incapacidad de los partidos y el Congreso para conectarse con los ciudadanos,

2. Véase en los siguientes enlaces las entrevistas al expresidente Ricardo Lagos (2016) y también al presidente Sebastián Piñera (2019): https://www2.latercera.com/noticia/ricardo-lagos-escobar-esta-es-la-peor-crisis-politicae-institucional-que-ha-tenido-chile/; https://www.cnnchile.com/pais/exclusivo-entrevista-sebastian-pinera-cuenta-publica_20190602/ 
pero también repetidos casos de corrupción que han ido minando la escasa confianza que había en la sociedad chilena: «los indicadores de un buen funcionamiento de una democracia -variable que aproxima el desempeño de las instituciones en un país- muestran que Chile, Alemania, España y Estados Unidos, por nombrar algunos, alcanzan el máximo nivel posible, y Francia obtuvo un punto menos que el máximo posible en 2014. Esto significa que la desconfianza en las instituciones puede coexistir con un razonable desempeño institucional, por ende, no es una condición suficiente para hablar de una crisis institucional» (CEP, 2017: 25).

Como se puede distinguir, se trata de diagnósticos distintos pero que convergen en la idea del distanciamiento entre representantes y sociedad, aunque difieren en torno a la intensidad del problema sociopolítico. En todo caso, el asunto no sólo estriba en torno a cómo los expertos y líderes políticos interpretan esta tensión entre clase política y ciudadanía, sino también en los cambios que habría que implementar para subsanar este socavamiento progresivo que han tenido las instituciones democráticas. Definitivamente, de no haber soluciones profundas, existe una nítida posibilidad de poner en riesgo la estabilidad del régimen democrático, tal cual se ha puesto en evidencia en el contexto del actual estallido social, algo que, por cierto, ya vaticinaba el informe del PNUD el año 2004, cuando indicaba que :«La creciente frustración por la falta de oportunidades y por los altos niveles de desigualdad, pobreza y exclusión social, se expresa en malestar, pérdida de confianza en el sistema politico, acciones radicalizadas y crisis de gobernabilidad, hechos que ponen en riesgo la propia estabilidad del régimen democrático» (PNUD, 2004: 25).

\section{El factor institucional}

En verdad, la situación de escisión entre política y sociedad, comenzó a ser realmente dimensionada como tal a partir del año 2011. A partir de ese año hasta la actualidad, se han desarrollado en Chile miles de movilizaciones y protestas sociales en las que se sigue demandando una mayor participación de la ciudadanía en las decisiones políticas (PNUD, 2014 y 2015b; Fuentes y Joignant, 2015; Heiss, 2016; Mayol, 2013; Rojas, 2012) y también un cambio en la orientación del modelo de desarrollo, sobre todo para reducir los altos niveles de desigualdad (DESOC, 2019; PNUD, 2015b).

Los síntomas sociales negativos, que ya se venían haciendo visibles al comienzo de esta década (Mayol, 2017), tuvieron su catarsis o mejor expresión bajo el acontecimiento de un estallido social a partir del mes de octubre de 2019. Éste ha consistido en masivas movilizaciones sociales desplegadas a lo largo de todo el país en forma simultánea, acompañadas de una inusitada violencia por parte de algunos sectores de la población; violencia que no se registraba desde las protestas contra la dictadura en 1983 y 1984 (Revilla, 2009; Moulian y Osorio, 2014). Pese al carácter violento del 
estallido social, las movilizaciones han contado con un fuerte apoyo de la sociedad chilena (DESOC, 2019: 6).

En efecto, la naturaleza de las demandas sociales durante esta década, han mostrado los alcances o límites de la institucionalidad vigente, en la medida en que éstas no pueden ser resueltas íntegramente sin un cambio profundo en las reglas del juego institucional (PNUD, 2014; Atria, 2013; Fuentes y Joignant, 2015; Atria y otros, 2013). Esto es así, básicamente, por la naturaleza política que tiene el diseño institucional existente, que consagra un tipo singular de democracia «limitada» (Garretón, 2015; Fuentes, 2012), centralista (García García, 2014), y que, además, define un determinado modelo de desarrollo socioeconómico de orientación neoliberal radical (Huneeus, 2014).

Es así que, tomando en consideración el carácter sistemático de las movilizaciones sociales, y en virtud de la significación que expertos y líderes le asignan al componente institucional, conviene colocar atención en la incidencia o impacto que ha tenido éste factor en el deterioro de las actitudes políticas de los chilenos. Desde la mirada tradicional de importantes autores del campo de la cultura política (Linz, 1978; Nie, Kim y Verba, 1987; Inglehart, 1991; Almond y Verba, 1970; Pateman, 2014; Diamond, Hartlyn y Linz, 1999; Pye, 1965), se trata de un elemento relevante, puesto que como se puede advertir, la situación radica, finalmente, en cómo los ciudadanos otorgan legitimidad a las instituciones que los gobiernan (Montero, Gunther y Torcal, 1998), la que debe ser significativa si se requiere un mayor "compromiso cívico» de la ciudadanía en los asuntos públicos, algo que a la fecha en el país sudamericano no estaría ocurriendo.

El problema de las instituciones en el caso chileno tiene larga data y se remonta, según varios autores, al momento de la transición a la democracia (Garretón, 2015; Godoy, 1999; Brunner, 1990; Boeninger, 1997). Este momento consiste en una coyuntura clave en la historia institucional del país, en el que la Concertación de partidos por la democracia asume el gobierno en el marco de un diseño institucional de «democracia autoritaria y protegida» (Pinochet, 1977): hecho político que es indepediente del debate transitológico de si la transición chilena fue pactada o impuesta (Godoy, 1999 y 2003; Garretón, 2015; Huneeus, 2014; Fuentes, 2012).

El diseño institucional de democracia protegida ha consistido en un conjunto de «enclaves autoritarios» que fueron elaborados en dictadura, y que han tenido como objetivo permanecer en democracia (García y Verdugo, 2015: 131). Éstos buscaban la transferencia de poder hacia dispositivos no democráticos (Garretón, 2015; Atria, 2013; Godoy, 2003; Siavelis, 2009; Fuentes, 2012; PNUD, 2014) con capacidad de veto al poder limitar la voluntad del ejecutivo y del Congreso. Entre estos se encontraban los senadores designados, el Tribunal Constitucional y el Consejo de Seguridad 
Nacional. Todas estas instituciones mencionadas, a través de la Constitución de 1980, lograban garantizar una evolución política en la que las Fuerzas Armadas podían deliberar y también vigilar el proceso político en democracia.

Aunque en 2005 las reformas constitucionales lograron subordinar el poder militar al poder civil (Fuentes, 2012; Domínguez, 2005), lo cierto es que las fuerzas del orden lograron tener durante 15 años representación política en el parlamento, permitiendo con ello una sobre-representación de la derecha afín a la dictadura mili$\operatorname{tar}$ (PNUD, 2014: 201). Esto, sin lugar a dudas, se transformó en un factor de distorsión del régimen democrático, que influyó negativamente en la representatividad $\mathrm{y}$, sobre todo, en la legitimidad del Congreso Nacional (Godoy, 2003). De hecho, así lo confirman algunos datos que muestran que, a una década de la transición, casi el 60\% de los ciudadanos clamaba por la supresión de los senadores designados, mientras poco menos del 30\% solicitaba su mantención en el Congreso (CERC, 2000).

La designación de senadores, también se vio reforzada con el sistema electoral binominal, que fue diseñado casi al terminar el período autoritario (Von Baer, 2006). La literatura especializada señala que este sistema, por su propia especificidad, buscaba excluir deliberadamente a una tercera fuerza política (Guzmán, 1993), además de conducir a las dos grandes coaliciones a un «empate» político. Esto, en la práctica, reproducía el clivaje democracia/autoritarismo en todas las elecciones de autoridades representativas (los partidos del Sí y los partidos del No) (Tironi, 1999, pág. 13). Aunque en un principio se pensó que esta situación sólo iba a beneficiar a la derecha, la verdad es que, en realidad, llevó tanto a la Concertación como a la oposición a monopolizar en casi un $97 \%$ los escaños durante todas las elecciones desde 1990 hasta el cambio de sistema electoral en 2015 (Navia y Garrido, 2015; Ruiz y Osorio, 2016). Como han demostrado varios analistas, esto contribuyó decididamente a la desafección en el electorado, ya que los ciudadanos sabían de antemano cómo se daría el resultado de las votaciones, lo que no provocaba ningún aliciente para participar (PNUD, 2014: 43; Torcal y Chhibber, 1995; Alcántara y Luna, 2004: 140).

Otro factor institucional principal que ha contribuido al socavamiento de las bases de la democracia es la Constitución. En efecto, se trata de una Carta que ha sufrido varias reformas desde 1980 hasta la fecha (siendo la Constitución más reformada en la historia de Chile) (Navarro, 2014), no obstante, como indican sus detractores, ella ha influido negativamente en la ciudadanía, básicamente, en dos dimensiones: una política y también en el desarrollo socioeconómico del país.

En la dimensión política, la Constitución no ha podido ser cambiada pese a los deseos de la mayoría de la población. Ciertamente, en plena movilización social de 2011, poco más del 60\% se declaraba a favor de una Nueva Constitución, esgri- 
miendo como fundamentos del cambio constitucional el origen ilegítimo de la Constitución y lo inservible de su contenido (PNUD, 2015a). Esta situación se repite en el contexto del actual estallido social en el país, aunque la cifra ha aumentado significativamente, sobrepasando el $90 \%$ de la población, además, con una extraordinaria nitidez respecto del mecanismo de cambio constitucional, ya que el 75,7\% de los ciudadanos declara su preferencia por una asamblea constituyente electa por ciudadanos (DESOC, 2019: 18) ${ }^{3}$.

En efecto, una de las críticas más fuertes que se le hacía al texto fundamental, era que éste hacía imposible lograr mayorías parlamentarias para cambiar la Constitución (Atria, 2013; Garretón, 2012; Fuentes, 2012), a lo que se suman las propias dificultades que contiene la misma Carta para su reemplazo. Se trata, al decir de sus críticos, de dispositivos que continúan «neutralizando a las mayorías», entre los que se encuentran los quórums supramayoritarios de reforma constitucional de dos tercios o tres quintos (dependiendo del capítulo de la Constitución) y también las Leyes Orgánicas Constitucionales (LOCE) (leyes vitales para el régimen militar), que requieren cuatro séptimos para su modificación o derogación (Heiss y Szmulewicz, 2018: 76-77). Estos recursos institucionales se ven reforzados con el control preventivo obligatorio que hace el Tribunal Constitucional en el caso de las LOCE, algo que no sucede con otro tipo de leyes 4 .

Ciertamente, los elementos mencionados estarían influyendo negativamente en la cultura política de la ciudadanía, al distorsionar el principio democrático que no permite a las fuerzas mayoritarias superar o trascender el diseño de democracia limitada. Lo anterior, permitiría verificar diagnósticos de autores como Linz (1978), Almond y Verba (1970), Pye (1965), Diamond, Hartlyn y Linz (1999), Pateman (2014), Montero, Gunther y Torcal (1998), entre otros, en los que se señala que la legitimidad que tienen las instituciones democráticas puede ser un factor fundamental para aumentar la confianza y el compromiso cívico de los ciudadanos. De lo contrario, ante la ausencia de estos elementos se podría poner en riesgo la estabilidad del régimen político (PNUD, 2004, 2012 y 2014), que es justamente lo que parece estar ocurriendo hoy día en Chile (DESOC, 2019).

3. La presión ejercida por la ciudadanía ha llevado al ejecutivo y al Congreso a llegar a un acuerdo para iniciar un proceso constituyente para una Nueva Constitución, el que tendrá lugar el mes de abril de 2020, a través de un plebiscito para preguntarle a la ciudadanía si quiere una Nueva Constitución, además de la selección de un mecanismo de cambio constitucional: una convención constituyente mixta (congresistas y ciudadanos) o una convención constituyente (sólo ciudadanos).

4. Según algunos autores, el Tribunal Constitucional opera en la práctica como una «tercera cámara» (Atria, 2013; Atria y otros, 2013), lo que implica que éste puede fallar sobre leyes ya aprobadas previamente por el Congreso Nacional. Este tipo de recurso ha sido negativo en la aprobación de varias leyes emblemáticas para la ciudadanía, como fue la dotación de mayores atribuciones sancionatorias del SERNAC, lo que buscaba proteger al consumidor de los abusos de las empresas (Mayol, 2017). 


\section{Institucionalidad y factor estructural del desarrollo}

Como señalaba anteriormente, el problema de la Constitución no es tan sólo político, sino que también comporta un elemento que impacta negativamente en el desarrollo socioeconómico del país, ya que consolida un modelo de orientación neoliberal radical (Linz y Stepan, 1996; Huneeus, 2014; Garretón, 2010 y 2012; Moulian, 1997; Mayol, 2013 y 2017; Atria y otros, 2013), que si bien ha permitido un crecimiento económico sostenido (De Gregorio, 2005), éste ha sido insuficiente para mejorar el problema de la desigualdad (PNUD, 2012 y 2014).

Se trata, en realidad, de una Carta Fundamental que consagra un principio de subsidiariedad que limita fuertemente el rol del Estado (Guzmán, 1991; Cordero, 2013; Van de Wyngard, 2013), delegando y transfiriendo gran parte de los servicios, bienes y recursos al sector privado (García García, 2014: 291). Esto último ha fomentado a nivel societal un exacerbado «individualismo", que ha sido corrosivo de cualquier forma de solidaridad social, algo que se expresa, claramente, por ejemplo, en la baja confianza interpersonal que tienen los chilenos (Latinobarómetro, 2018: 47; WVSMORI, 2018: 75). Esto aleja en demasía el tipo de individualismo que tiene lugar en el país sudamericano respecto de lógicas individualistas inherentes a las sociedades que tienen Estados del bienestar, en las que se logra equilibrar las libertades individuales y la solidaridad social (Inglehart y Welzel, 2006; Esping-Andersen, 2015).

Por el contrario, en el caso chileno, parece ser que la propia Carta Fundamental busca transferir a los propios individuos la responsabilidad de satisfacer sus necesidades, prescindiendo en buena medida del Estado en aspectos básicos de la vida social como es la salud, la educación, la seguridad social, la vivienda, entre otro tipo de derechos sociales. Así formula Van de Wyngard (2013) el rol del Estado que confiere la actual Constitución: "Bajo la Constitución de 1980 se define el rol del Estado como subsidiario y se prioriza como eje del desarrollo el ejercicio de la libertad y el consiguiente emprendimiento de las personas. El Estado deja de asumir un rol paternalista y entrega la responsabilidad de proveerse la satisfacción de las necesidades a las propias personas y a su capacidad de esfuerzo, trabajo y superación (...) Ahora las personas han ido progresivamente entendiendo y asumiendo que la satisfacción de las necesidades de salud, educación, trabajo, seguridad social, desarrollo económico etc., son asuntos que dependen prioritariamente de ellas mismas y que ya no estará siempre el Estado para proveérselas. Es indudable que ese camino ha sido duro para algunos, pero en definitiva ha generado una profunda transformación sociocultural, sobre todo en las generaciones más jóvenes, que entienden que deben ser capaces por sí mismos de configurar sus propias existencias, prescindiendo en buena medida del Estado» (pág. 281).

Así, la Constitución delega en los propios individuos y también los «cuerpos intermedios» (Guzmán, 1991) la provisión de servicios sociales de toda índole. Esto 
en la práctica ha significado la existencia de un Estado incapacitado para participar e intervenir en la vida social en forma activa, ya que el diseño institucional consagra al mercado como principal asignador y distribuidor de recursos (Linz y Stepan, 1996). Esto último, según diversos autores, ha contribuido, definitivamente, a fomentar la concentración de dichos recursos y bienes en ciertos grupos sociales y económicos en detrimento de la gran mayoría de la población (Atria y otros, 2013; Fuentes y Joignant, 2015; Huneeus, 2014; Segovia y Gamboa, 2015; cfr. Van de Wyngard, 2015; cfr. Cordero, 2015), lo que ha favorecido un aumento del malestar social sobre todo por la percepción de extrema concentración que hay en el país (CERC, 2019).

Pues bien, como es posible distinguir, lo anterior lleva insoslayablemente al problema del desarrollo socioeconómico, que como se puede observar en el caso chileno, está estrechamente ligado a las instituciones vigentes, como es el caso de la actual Constitución. En tal sentido, se trata de un asunto importante a subrayar, en la medida en que dentro de la amalgama de factores que pueden estar influyendo en producir una "crisis institucional», se encuentra también el factor distributivo, que conforme a lo que se ha señalado, debe ser analizado tomando en consideración el peso de las instituciones sobre su orientación.

Al respecto, una basta literatura avala la importancia de un desarrollo socioeconómico avanzado en la configuración de actitudes políticas favorables hacia la democracia, fortaleciendo el compromiso cívico de la ciudadanía con los asuntos públicos. En esa línea, varios autores y organismos internacionales que se han dedicado a analizar esta dimensión de la política, han sido insistentes en verificar la relevancia de la distribución de recursos económicos y sociales en cómo los ciudadanos perciben y se orientan políticamente hacia sus regímenes políticos (Lipset, 1970; Inglehart, 1991; Inglehart y Welzel, 2006; Huntington, 1991; Rostow, 1972; Linz y Stepan, 1996; Stiglitz, 2012; Przeworski, 1994; cfr. Diamond, 1993).

En efecto, tomando en consideración algunos postulados provenientes de estas contribuciones, se puede decir que en el caso chileno ha ocurrido una situación "paradójica», en la medida, en que se trata de un país que ha tenido un desarrollo económico in crescendo, con un importante crecimiento económico en forma sostenida desde el retorno de la democracia hasta el día de hoy, siendo de los más altos de la región por largo tiempo (Banco Mundial, 2018; PNUD, 2017). Este crecimiento, además, ha ido acompañado de una elogiada gobernabilidad democrática (Domínguez, 2005; de Gregorio, 2005), siendo éste uno de los factores que ha llevado a diversos organismos internacionales a valorar positivamente la democracia chilena nivel internacional.

Así, dentro de este desarrollo, se destaca un mejoramiento importante de la calidad de vida de los chilenos (OCDE, 2018). Parte de este mejoramiento se produce, 
como bien decíamos, sobre todo, por la vía del mercado, con la activa participación del sector privado en el ámbito de la educación, lo que ha aumentado significativamente la cobertura en esta materia (OCDE, 2015: 2). Esto también vale para salud, lo que ha permitido a Chile estar bien posicionado dentro de los países de la OCDE. También, se subrayan los notables avances en materia de reducción de la pobreza, que ha disminuido de casi un 40\% en 1990 a un 11,7\% en 2015 (Ministerio del Desarrollo Social, 2017: 13).

Pero a pesar de los avances mencionados, siguen persistiendo graves problemas de desigualdad socioeconómica y concentración de la riqueza, que no han podido ser solucionados por los gobiernos democráticos desde 1990 hasta 2019 bajo la estrategia de democratización sobre la base únicamente del crecimiento económico.

Efectivamente, el país sudamericano es de los más desiguales de América Latina, sólo superado por Brasil, Costa Rica y México. Tiene un coeficiente Gini de 47,7 según el Banco Mundial en 2018, lo que representa una cifra alta si se compara con otros países con democracias avanzadas, como es el caso, por ejemplo, de España y Noruega, que en el mismo año presentan un coeficiente Gini de 36,2 y 27,5, respectivamente ${ }^{5}$. Estos indicadores, además, son coherentes con la alta concentración de la riqueza, que aunque es bien sabido es un fenómeno global (Piketty, 2015; Stiglitz, 2012), lo cierto es que en el caso del país sudamericano siembra dudas respecto a su sostenido crecimiento económico, que pareciera ser impotente respecto a la disminución de la desigualdad. Algunos datos ilustran esta situación: por ejemplo, un informe reciente de la CEPAL señaló que el $1 \%$ más rico del país concentra el 26,5\% de la riqueza (CEPAL, 2018: 62). Esta cifra no difiere de datos elaborados por la OCDE poco tiempo antes, desde donde se señala que en 2015, el decil más rico de Chile era 26 veces más alto que el decil más pobre (OCDE, 2015:3).

El panorama social descrito, muestra que el problema de la distribución desigual de los recursos ha tenido un impacto negativo en la participación de los ciudadanos en política. Esto puede ocurrir, entre otros factores, porque la sociedad chilena percibe que el «elogiado» crecimiento económico no se traduce necesariamente en un mejoramiento de la situación social del país y de los hogares. Esta percepción se verifica en la evaluación crítica que tienen los chilenos del crecimiento económico, puesto que sólo un $17 \%$ de la población manifiesta haberse beneficiado de esta situación. En el otro lado de la acera, una gran mayoría declara que sólo ha beneficiado a quienes tienen más riqueza (CERC-MORI, 2011; Latinobarómetro, 2017: 25). Esta percepción negativa sobre una desigual distribución de la riqueza, ilustra la

5. Fuente: Banco Mundial en 2018. Enlace:

https://datos.bancomundial.org/indicador/SI.POV.GINI?locations=CL\&year_high_desc=false Visitado el día 23 de diciembre de 2018. 
tesis de Inglehart y Welzel (2006), quienes manifiestan que desarrollo y crecimiento económico no implican lo mismo: «(...) el nivel de desarrollo económico de una sociedad es un factor de predicción mejor de la democratización que su tasa de crecimiento económico. De hecho, las tasas de crecimiento económico son siempre engañosas como factor de predicción de la democracia, e incluso pueden tener el signo contrario» (Inglehart y Welzel, 2006: 60)».

Pues bien, dentro de la amalgama de factores que intervienen y configuran la alicaída cultura política de los chilenos, es posible que el factor estructural mencionado sea contributivo en explicar, en forma importante, la baja confianza interpersonal, aunque también parte de la baja confianza en las instituciones (Putnam, 2000; LAPOP, 2012: 92). Esto es así por todo lo antes mencionado, pero también porque la literatura muestra que en momentos históricos en que el factor distributivo fue menos regresivo (Maddison, 1989; Gangas, 2003; Larrañaga, 2001; Beyer, 1997), el interés en la política por parte de la ciudadanía tuvo un considerable aumento.

Lo anterior se puede apreciar si se observan algunas cifras del desarrollo chileno a lo largo de su historia. Es el caso, por ejemplo, de los gobiernos de la década del sesenta: Jorge Alessandri Rodríguez (1958-1964), Eduardo Frei Montalva (19641970) y Salvador Allende (1970-1973). En efecto, durante este contexto histórico, la pobreza se disminuyó a poco menos del 15\% (Piñera, 1978: 8), y, además, la sociedad chilena presentó una disminución en sus niveles de desigualdad (Larrañaga, 2001: 8), llegando a un coeficiente Gini promedio de 0,48 entre 1958 y 1970: esto ha llevado a los analistas a considerar esta etapa como la menos regresiva en la historia del país (Maddison, 1989; Larrañaga, 2001; Gangas, 2003).

Posteriormente, bajo la dictadura militar, la desigualdad aumentó significativamente, llegando a un coeficiente Gini de 0,57 a fines del período autoritario (Larrañaga, 2001). Esta mala distribución de la riqueza se ha ido contrarrestando por los gobiernos democráticos en forma muy gradual, llegando en 2018 a cifras similares a las que había en el Gini antes del golpe militar de 1973. Esto pone en evidencia que el elevado crecimiento económico que ha tenido el país ha sido insuficiente para avanzar hacia el desarrollo con una distribución más igualitaria y menos regresiva (Ffrench-Davis, 2003).

Sin embargo, lo que hay que tomar en consideración es que durante la década del sesenta aumentó el interés por la política en la ciudadanía, lo que se expresó en un crecimiento significativo del padrón electoral. Como se puede distinguir en el gráfico 2, si en 1958 votaba el 35\% de la población, entre 1960 y 1970, la participación aumentó sobre un 65\% (Lagos, 2017) y aquel porcentaje de dos dígitos que en 1958 era indiferente ante el régimen político, en 1970 disminuyó a menos de un 10\% (Navia y Osorio, 2015; Huneeus, 1987). 
Gráfico 2

Participación electoral, 1925-2016

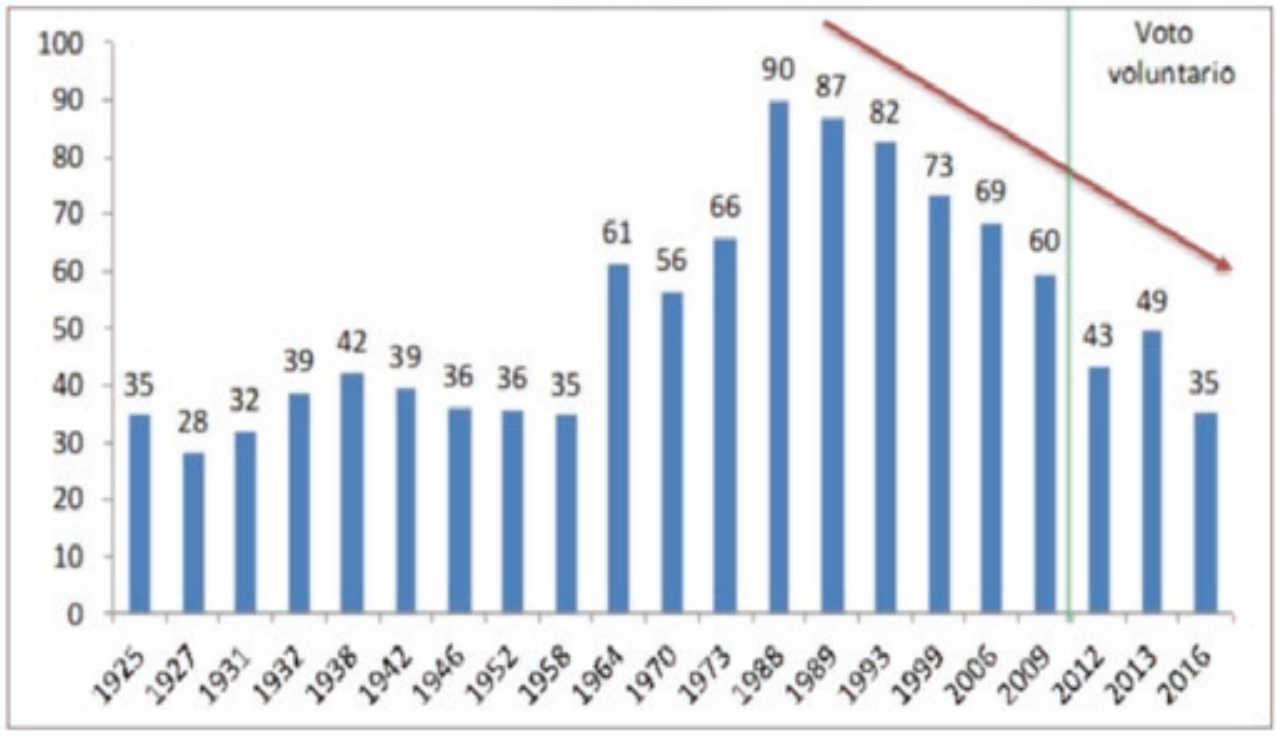

Fuente: Lagos (2017)

En todo caso, no hay que perder de vista que lo anterior se puede deber a diversos factores, como fue el destacado desarrollo institucional del país, que fue clave en el proceso de profundización de la democracia (Sartori, 1976; Pinto, 1973); o el acelerado proceso de polarización, que llevó a la ciudadanía a tomar posición en algún tercio del sistema de partidos (Moulian, 1994; Ruiz, 2005; Valenzuela, 1978), entre otras variables políticas que no se pueden dejar de tener en cuenta si se quiere enriquecer el análisis. Reconociendo estos elementos, también es evidente que, si se presta atención a lo que señala la literatura entre desarrollo socioeconómico y democracia, el factor distributivo parece tener un peso que puede ser relevante $y$, en ocasiones, ser decisivo para entender cómo un mejoramiento de la situación socioeconómica puede incidir positivamente en las actitudes políticas hacia la democracia, algo que queda en evidencia en el caso chileno: antes del golpe militar con un mayor compromiso cívico y desde el retorno de la democracia hasta la fecha con una alta desafección (Osorio, 2019; Segovia y Gamboa, 2015).

A mayor abundamiento, se podría sostener que el factor estructural mencionado puede llegar a ser más decisivo que otros factores institucionales como han sido los numerosos casos de corrupción que ha experimentado el país en el último tiempo. Se 
puede sostener esta afirmación, especialmente, por dos razones: en primer lugar, porque la desafección viene desarrollándose desde bastante tiempo antes que el destape de los casos de corrupción que han remecido al país (Matamala, 2015). En tal sentido, muy probablemente, los casos de corrupción sólo han contribuido a acelerar aún más el socavamiento de las bases culturales de la democracia chilena.

En segundo lugar, como señalan algunos expertos, la corrupción es un fenómeno que se produce en muchos países del mundo que tienen regímenes democráticos (Gruenberg, 2007; Ariño y Romero, 2016; Stiglitz, 2012), sin embargo, también es cierto que este problema se percibe como más intolerable en la ciudadanía cuando estos países tienen una distribución muy desigual de la riqueza, como es el caso de Chile (OCDE, 2018; CEPAL, 2018).

Así, en otros países iberoamericanos con distribuciones menos regresivas y con un alto nivel de percepción de corrupción, el apoyo a la democracia no necesariamente ha bajado. Es el caso de países como España, que detenta un lugar más alto que Chile en el ranking de Corruption Perceptions Index (2018) y cuyo apoyo a la democracia en 2018 llega a un 86\% (28\% más que Chile) (Fundación Alternativas, 2019: 19). Otros países con democracias menos avanzadas, como es el caso de Argentina, el apoyo a la democracia en 2018 es igual que el de Chile (58\% según la medición de Latinobarómetro de 2018), aun cuando el país trasandino ocupa el lugar número 40 en el Corruption Perceptions Index (2018), con veintisiete lugares sobre Chile. Esto último parece indicar que la corrupción es un problema gravísimo en la forma en que los ciudadanos perciben a las élites (Ariño y Romero, 2016), sin embargo, aunque siempre puede ser materia de debate intelectual, parece ser que la desigualdad es un tanto más incisiva en la cultura política de los ciudadanos, y de alguna manera, así lo confirma la literatura y la evidencia empírica (Latinobarómetro, 2017 y 2018; LAPOP, 2016; PNUD, 2014; Inglehart y Welzel, 2006; Rostow, 1972).

\section{Conclusiones}

La literatura especializada que se ha ocupado sobre las actitudes políticas ha sido insistente en señalar la complejidad de factores que pueden formar, intervenir y condicionar la cultura política nacional en los distintos países. Dentro de estos factores, las instituciones juegan un rol fundamental, sobre todo cuando éstas están legitimadas ante la ciudadanía, lo que aumenta la confianza y fortalece la participación política de los grupos y personas en los asuntos públicos (Almond y Verba, 1970; Putnam, 2000; Linz, 1978; Pateman, 2014; Montero, Gunther y Torcal, 1998; Diamond, Hartlyn y Linz, 1999; Nie, Kim y Verba, 1987; Pye, 1965).

Pero no bastan solo instituciones democráticas para que haya democracia. Es por ello que también se ha destacado la importancia del factor del desarrollo socioeco- 
nómico para la emergencia y fortalecimiento de los regímenes democráticos. Así lo ha mostrado la literatura a través de sistemáticas mediciones, desde donde se subraya la relevancia que tiene para la democracia la propagación de sociedades con altos niveles de igualdad. Esto, según los expertos, es básico para fomentar la producción de cambios culturales, sociales y económicos que orienten a los ciudadanos a demandar instituciones democráticas y su permanencia en el tiempo, tal cual se ha venido desarrollando desde la «tercera ola» (third wave) hasta el día de hoy (Inglehart, 1991; Inglehart y Welzel, 2006; Lipset, 1970; Rostow, 1972; Huntington, 1991; Linz y Stepan, 1996; Stiglitz, 2012; Przeworski, 1994).

Sobre la base de estos postulados ya mencionados, se puede señalar que en el caso chileno, algunos factores institucionales y estructurales analizados en este artículo, han sido contributivos en la producción de una "crisis institucional», cuya expresión más nítida ha sido el violento estallido social que se ha iniciado en octubre de 2019 y cuyo desenlace es aún incierto.

Lo anterior se puede producir, como se ha intentado mostrar, por la presencia de un diseño institucional que ha limitado la «democracia plena» a través de sus «enclaves autoritarios», los que han operado como recursos institucionales para neutralizar a las mayorías. Esto ha intensificado la falta de legitimidad para la ciudadanía, lo que ha sido decisivo en producir una creciente desconfianza y desafección política hacia instituciones democráticas como los partidos, el Congreso, el gobierno, entre otras.

Se suma a lo anterior el factor estructural del desarrollo socioeconómico, que ha sido insuficiente en disminuir las brechas sociales en la sociedad chilena, tanto en el pasado como en el presente. Se trata de una sociedad que ha experimentado una estabilidad democrática y económica importante durante varias décadas, en las que el crecimiento económico ha sido alto en relación al resto de los países de la región. No obstante, persisten serios problemas distributivos que han aumentado el malestar social en la ciudadanía, lo que ha contribuido a la movilización sistemática de los chilenos, tal cual se ha podido ver bajo el actual estallido social en el país. Esta situación, confirma la premisa señalada por el informe del PNUD de 2004, en la que se mencionaba que los problemas de las desigualdades podían desencadenar un escenario social imprevisto que podía poner en riesgo la propia democracia.

\section{Bibliografía}

ALCÁNTARA, Manuel., y LUNA, Juan P. (2004) «Ideología y competencia partidaria en dos post-transiciones: Chile y Uruguay en perspectiva comparada, Revista de Ciencia Política, 24 (1), 126-168.

ALMOND, Gabriel., y VERBA, Sidney (1970) Cultura Cívica. Estudio sobre la participación política democrática en cinco naciones, Madrid, Euramérica S.A. 
ARIÑO, Antonio y ROMERO, Juan (2016) La secesión de los ricos, Barcelona, Galaxia Gutenberg.

ATRIA, Fernando (2013) La Constitución tramposa, Santiago, LOM.

ATRIA, Fernando, LARRAÍN, Guillermo, BENAVENTE, José, COUSO, Javier y JOIGNANT, Alfredo (2013) El otro modelo: del orden neoliberal al régimen de lo público, Santiago, Random House Mondadori.

BARGSTED, Nicolas y SOMMA, Matías (2018) «La cultura política: diagnóstico y evolución» en C. HUNEEUS y AVENDAÑO, O. (eds.), El sistema político de Chile, Santiago, Lom.

BOENNINGER, Edgardo (1997) Democracia en Chile: lecciones para la gobernabilidad, Santiago, Andrés Bello.

BOURDIEU, Pierre (2001) El campo político, La Paz, Plural editores.

BRUNNER, José (1990) «Chile: claves de una transición pactada», Nueva Sociedad (106), 6-12.

Centro de Estudios Públicos (2017) Informe encuesta CEP 2016: ¿Malestar en Chile? Santiago, CEP.

CEPAL (2018) Panorama social de América Latina, Santiago, CEPAL.

CERC-MORI (2011) Barómetro de la Política mayo 2011, Santiago, CERC-MORI.

CERC-MORI (2019) Barómetro de la política mayo 2019, Santiago, CERC-MORI.

CORDERO, Gonzalo (2015) «La solución no es constitucional» en C. FUENTES y A. JOIGNANT (eds.), La solución constitucional: plebiscitos, asambleas, congresos, sorteos y mecanismos híbridos, Santiago, Catalonia.

DE GREGORIO, José (2005) «Crecimiento económico en Chile: evidencia, fuentes y perspectivas», Estudios Públicos (98), 1-86.

DEL CAMPO, Esther (2007) «Democracia y desarrollo en Chile: el aprendizaje institucional de las reformas», Pensamiento Iberoamericano, 237-263.

DESOC (2019) Encuesta Termómetro social, octubre 2019, Santiago.

DIAMOND, Larry (2003) «¿Puede el mundo entero ser democrático? Democracia, desarrollo y factores internacionales», Revista española de Ciencia política, núm. 9, 9-38.

DIAMOND, Larry, HARTLYN, Jonathan y LINZ, Juan (1999) «Introduction: Politics, Society, and Democracy in Latin America», en L. DIAMOND, J. HARTLYN, J. LINZ y S. MARTIN (eds.), Democracy in Developing Countries: Latin America, Colorado, Lynne Rienner Publishers, Inc.

DOMÍNGUEZ, Jorge (2005) «Construcción de gobernabilidad democrática en América Latina. Una evaluación de la década de 1990», en J. DOMÍNGUEZ y M. SHIFTER (eds.), Construcción de gobernabilidad democrática en América Latina, Bogotá, Fondo de cultura económica. 
ESPING-ANDERSEN, Gøsta (2015) Los tres grandes retos del Estado del bienestar, Barcelona, Ariel.

FFRENCH-DAVIS, Ricardo (2003) Entre el neoliberalismo y el crecimiento con equidad. Tres décadas de política económica en Chile, Santiago, Comunicaciones Noreste Ltda.

FUENTES, Claudio (2012) El Pacto: Poder, Constitución y prácticas políticas en Chile (1990-2010), Santiago, UDP ediciones.

FUENTES, Claudio y JOIGNANT, Alfredo (2015) «La solución constitucional: rutas de salida del antiguo orden y estrategias de entrada a una Nueva Constitución», en C. FUENTES y A. JOIGNANT (eds.), La solución constitucional: plebiscitos, asambleas, congresos, sorteos y mecanismos híbridos, Santiago, Catalonia.

Fundación Alternativas (2019) Informe sobre la democracia en España 2018, Madrid, Fundación Alternativas.

GANGAS, Pilar (2003) «Desigualdad y pobreza: América Latina y Europa desde 1950», Política y Cultura (20), 29-51.

GARCÍA García, José(2014) «Minimalismoeincrementalismoconstitucional», Revista chilena de derecho, 41(1), 267-302. Doi: 10.4067/s0718-34372014000100011

GARCÍA García, J y VERDUGO, Sergio (2015) «Un camino a la Constitución de 2020: un proceso constituyente que una y no divida a los chilenos», en C. FUENTES, y A. JOIGNANT (eds.), La solución constitucional: plebiscitos, asambleas, congresos, sorteos y mecanismos híbridos, Santiago, Catalonia.

GARRETÓN, Manuel A. (2010) «La problemática de América Latina y sus respuestas en juego» en M. SALAZAR y A. OSORIO (eds.), Democracia y antagonismos en el Chile contemporáneo. Perspectivas postransicionales, Santiago, Akhilleus.

GARRETÓN, Manuel A. (2012) Neoliberalismo corregido y progresismo limitado. Los gobiernos de la Concertación (1990-2010), Santiago, ARCIS-CLACSO.

GARRETÓN, Manuel A. (2015) Las ciencias sociales en la trama de Chile y América Latina. Estudios sobre transformaciones sociopoliticas y movimiento social, Santiago, LOM.

GARRETÓN, Manuel A. (2016) «Crisis de representación, movilizaciones sociales y elecciones presidenciales 2013 en Chile», en F. MAYORGA (ed.), Elecciones $y$ legitimidad democrática en América Latina, La Paz, CESU-UMSS, CLACSO, IESE y Plural editores.

GARRETÓN, Manuel A. (2017) «El proyecto de transformación y la crisis políticoinstitucional de la sociedad chilena. El gobierno de Bachelet entre 2014-2016», en C. ARQUEROS, y Á. IRIARTE (eds.), Chile y América Latina: crisis de las izquierdas del siglo XXI, Santiago, UDD e IRP. 
GODOY, Óscar (1999) «La transición chilena a la democracia: pactada», Estudios Públicos 74, 79-106.

GODOY, Óscar (2003) «Parlamento, presidencialismo y democracia protegida», Revista de Ciencias Política, 23 (2),7-42. Doi: 10.4067/s0718-090x2003000200002

GRUENBERG, Cristián (2007) El costo de la democracia: poder económico y partidos políticos, Buenos Aires, Capital intelectual.

GUZMÁN, Jaime (1991) «El miedo y otros escritos», en A. FONTAINE (comp.), El pensamiento de Jaime Guzmán, Santiago, Centro de Estudios Públicos.

HEISS, Claudia (2016) «Soberanía popular y momento constituyente en el debate sobre cambio constitucional en Chile», Revista Anales séptima serie (10), Universidad de Chile. Doi: 10.5354/0717-8883.2016.43145

HEISS, Claudia y SZMULEWICZ, Esteban (2018) «La Constitución Política de 1980», en C. HUNEEUS, y O. AVENDAÑO (eds.), El sistema político de Chile, Santiago, Lom.

HUNEEUS, Carlos (1987) Los chilenos y la política: cambio y continuidad bajo el autoritarismo, Santiago, CERC.

HUNEEUS, Carlos (2014) La democracia semisoberana: Chile después de Pinochet, Santiago, Taurus.

INGLEHART, Ronald (1991) El cambio cultural en las sociedades industriales, Madrid, Centro de investigaciones sociológicas.

INGLEHART, Ronald y WELZEL, Christian (2006) Modernización, cambio cultural y democratización: la secuencia del desarrollo humano, Madrid, Centro de investigaciones sociológicas.

LAGOS, Marta (2017) «La peor de las elecciones presidenciales desde 1990», El Mostrador, 14 de noviembre.

LAPOP (2012) Cultura política de la democracia en Chile y en las Américas, Vanderbilt University

LAPOP (2014) Cultura política de la democracia en Chile y las Américas, Vanderbilt University.

LAPOP (2016) Cultura política de la democracia en Chile y en las Américas, Vanderbilt University.

LARRAÑAGA, Óscar (2001) «Distribución de ingresos en Chile: 1958-2001», Documento de trabajo, Departamento de economía, Santiago, Universidad de Chile.

LATINOBARÓMETRO (2017) Informe 2017, Buenos Aires, Latinobarómetro. LATINOBARÓMETRO (2018) Informe 2018, Buenos Aires, Latinobarómetro. LINZ, Juan (1978) La quiebra de las democracias, Madrid, Alianza Universidad. 
LINZ, Juan y STEPAN, Alfred (1996) Problems of Democratic Transition and Consolidation, Baltimore, The John Hopkins University Press.

LIPSET, Seymour (1970) El hombre político: las bases sociales de la política, Madrid, Tecnos.

LUNA, Juan P y ROSENBLATT, Fernando (2012) «¿Notas para una autopsia? Los partidos políticos en el Chile actual», en F. DIAZ, y L. SIERRA (eds.), Democracia con partidos, Santiago, CEP y CIEPLAN.

MADDISON, Angus (1989) The World economy in the 20th Century, OECD, Development Centre Studies.

MATAMALA, Daniel (2015) Poderoso caballero: el peso del dinero en la política chilena, Santiago, Catalonia.

MAYOL, Alberto (2013) El derrumbe del modelo: la crisis de la economía de mercado en el Chile contemporáneo, Santiago, Lom.

MAYOL, Alberto (2017) Autopsia: ¿de qué se murió la élite chilena?, Santiago, Catalonia.

MONTERO, José R., GUNTHER, Richard y TORCAL, Mariano (1998) «Actitudes hacia la democracia en España: legitimidad, descontento y desafección», REIS, vol. 83, 9-49. Doi: 10.2307/40184120

MOULIAN, Tomás (1994) La forja de ilusiones: el sistema de partidos 1932-1973, Santiago, ARCIS-FLACSO.

MOULIAN, Tomás (1997) Chile actual: Anatomía de un mito, Santiago, ARCISLOM.

MOULIAN, Tomás y OSORIO, Alejandro (2014) Tiempos modernos: fragmentos de historia del Chile contemporáneo (1891-1990), Santiago, editorial Ayún.

NAVARRO, Enrique (2014) «Reformas a la Constitución chilena», Revista de Derecho Público, edición especial, 13-23. Doi: 10.5354/0719-5249.2014.31672

NAVIA, Patricio y OSORIO, Rodrigo (2015) «Las encuestas de opinión pública en Chile antes de 1973», Latin American Research Review, 50 (1), 117-139. Doi: 10.1353/lar.2015.0009

OCDE (2018) Estudios económicos de la OCDE: Chile, Paris, OECD Publishing.

OECD (2015) Education at a Glance: OECD Indicators: Chile. Paris, OECD Publishing. OSORIO, Alejandro (2019) La cultura política de la élite empresarial chilena. Un análisis comparado de los dirigentes gremiales de la Sociedad Nacional de Agricultura y la Sociedad de Fomento Fabril (2018-2019). Tesis para optar al grado de doctor, Madrid, Universidad Complutense de Madrid.

PATEMAN, Carole. (2014) Participación y teoría democrática, Buenos Aires, Prometeo.

PIKETTY, Thomas (2015) El capital en el siglo XX, Barcelona, RBA. 
PINTO, Anibal (1973) Chile, un caso de desarrollo frustrado, Santiago, Editorial Sudamericana.

PIÑERA, Sebastián (1978) Evolución de la pobreza en Chile: periodos (1940-1954; 1954-1958), Santiago, proyecto interinstitucional de pobreza en América Latina.

PNUD (2004) El poder: ¿para qué y para quién?, Santiago, Programa de Naciones Unidas para el Desarrollo.

PNUD (2012) Bienestar subjetivo: el desafío de repensar el desarrollo, Santiago, Programa de Naciones Unidas para el Desarrollo.

PNUD (2014) Auditoria a la democracia: más y mejor democracia para un Chile inclusivo, Santiago, Programa de Naciones Unidas para el Desarrollo.

PNUD (2015a) Opinión ciudadana y cambio constitucional: análisis desde la opinión pública, Santiago, Programa de Naciones Unidas para el Desarrollo.

PNUD (2015b) Los tiempos de la politización, Santiago, Programa de Naciones Unidas para el Desarrollo.

PNUD (2017) Desiguales. Orígenes, cambios y desafíos de la brecha social en Chile, Santiago, Programa de las Naciones Unidas.

PRZEWORSKI, Adam (1994) Democracia y mercado: reformas políticas y económicas en la Europa del Este y América Latina, Cambridge, Cambridge University Press.

PUTNAM, Robert (2000) «Introducción» en R. PUTNAM (ed.), El declive del capital social: studio internacional sobre las sociedades y el sentido comunitario, Galaxia Gutenberg, Barcelona

PYE, Lucian (1965) «Introduction: Political Culture and Political Development», en L. PYE \& S. VERBA (eds.), Political Culture and Political Development, Princeton, Princeton University Press.

REVILLA, Marisa (2009) «Chile: actores populares en la protesta social, 1983-1984», América Latina hoy, 1, 61-65.

ROJAS, Jorge (2012) La sociedad bloqueada: movimiento estudiantil, desigualdad y despertar de la sociedad chilena, Concepción, RIL editores.

RUIZ, Leticia (2005) «Polarization in the Chilean Party System: Changes and Continuities, 1990-1999». WP, 236, Institut de Ciències Politiques i Socials, $1-67$.

RUIZ, Leticia y OSORIO, Alejandro (2016) «Chile se rediseña: balance de cambio en las reglas electorales», Revista Latinoamericana de política comparada, 11, 57-68. ROSTOW, Walt (1972) Política y etapas de crecimiento, Madrid, Dopesa.

SARTORI, Giovanni (1976) Party and Party Systems, Cambridge, Cambridge University Press. 
SEGOVIA, Carolina y GAMBOA, Ricardo (2015) «Imágenes de desigualdad en Chile: el impacto de factores económicos y políticos», Papel político, 20 (2), 481500. Doi: 10.11144/javeriana.papo20-2.idci

SIAVELIS, Peter (2009) «Enclaves de la transición y la democracia chilena», Revista de Ciencia Política, 29 (1), 3-21. Doi: 10.4067/s0718-090x2009000100001

STIGLITZ, Joseph (2012) El precio de la desigualdad, Madrid, Taurus.

TIRONI, Eugenio (1999) La irrupción de las masas y el malestar de las elites, Santiago, Grijalbo S.A.

TORCAL, Mariano y CHHIBBER, Pradeep (1995) «Élites, cleavages y sistema de partidos en una democracia consolidada: España (1986-1992)», Reis 69. Doi: $10.2307 / 40183775$

VALENZUELA, Arturo (1978) El quiebre de la democracia en Chile, Santiago, FLACSO.

VERBA, Sidney, NORMAN, Nie y KIM, Jae on (1987) Participation and Political Equality: A Seven Nation Comparison, Chicago, University of Chicago Press.

VON BAER, Enna (2009) «Sistema binominal: consensos y disensos» en A. FONTAINE, C. LARROULET, J. NAVARRETE e I. WALKER (eds.), Reforma al sistema electoral chileno, Santiago, PNUD, CEP, Libertad y Desarrollo, Proyectamérica y Cieplan.

WVS-MORI (2018) Informe World Values Survey séptima ola enero 2018, Santiago, WVS-MORI. 